\title{
Policy and Science for Global Health Security: Shaping the Course of International Health
}

\author{
Kavita M. Berger ${ }^{1, *}$, James L. N. Wood ${ }^{2}$ (D) Bonnie Jenkins ${ }^{3,4}$, Jennifer Olsen ${ }^{5}$, \\ Stephen S. Morse ${ }^{6}$, Louise Gresham ${ }^{7}$, J. Jeffrey Root ${ }^{8}$, Margaret Rush ${ }^{1}$, David Pigott ${ }^{9,10}$, \\ Taylor Winkleman ${ }^{11}$, Melinda Moore ${ }^{12,+}$, Thomas R. Gillespie ${ }^{13,14}{ }^{\oplus}$, Jennifer B. Nuzzo ${ }^{15}$,
} Barbara A. Han ${ }^{16}{ }^{(1)}$, Patricia Olinger ${ }^{17}$, William B. Karesh ${ }^{18}$, James N. Mills ${ }^{13}$, Joseph F. Annelli ${ }^{19}$, Jamie Barnabei ${ }^{20}$, Daniel Lucey ${ }^{21}$ and David T. S. Hayman ${ }^{22, *(1)}$

1 Gryphon Scientific, LLC, 6930 Carroll Avenue, Suite 810, Takoma Park, MD 20912, USA; margaret@gryphonscientific.com

2 Disease Dynamics Unit, Department of Veterinary Medicine, University of Cambridge, Madingley Road, Cambridge CB3 0ES, UK; jlnw2@cam.ac.uk

3 Brookings Institution, 1775 Massachusetts Avenue NW, Washington, DC 20036, USA; bonniedjenkins@gmail.com

4 Women of Color Advancing Peace, Security and Conflict Transformation, 3695 Ketchum Court, Woodbridge, VA 22193, USA

5 Rosalynn Carter Institute for Caregiving, Georgia Southwestern State University, 800 GSW State University Drive, Americus, GA 31709, USA; jenolsen.drph@gmail.com

6 Department of Epidemiology, Mailman School of Public Health, Columbia University, 722 West 168th St., New York, NY 10032, USA; ssm20@cumc.columbia.edu

7 Ending Pandemics and San Diego State University, San Diego, CA 92182, USA; lgresham@sdsu.edu

8 U.S. Department of Agriculture, National Wildlife Research Center, Fort Collins, CO 80521, USA; Jeff.Root@aphis.usda.gov

9 Institute for Health Metrics and Evaluation, Department of Health Metrics Sciences, University of Washington, 2301 Fifth Avenue, Suite 600, Seattle, WA 98121, USA; pigottdm@uw.edu

10 Wellcome Centre for Human Genetics, Nuffield Department of Medicine, University of Oxford, Roosevelt Drive, Oxford OX3 7BN, UK

11 Next Generation Global Health Security Network, Washington, DC 20001, USA; t.winkleman.dvm@gmail.com

12 RAND Corporation, 1200 South Hayes St., Arlington, VA 22202, USA

13 Population Biology, Ecology, and Evolution Program, Emory University, Atlanta, GA 30322, USA; thomas.gillespie@emory.edu (T.R.G.); wildlifedisease@gmail.com (J.N.M.)

14 Department of Environmental Health, Rollins School of Public Health, 1518 Clifton Road, Atlanta, GA 30322, USA

15 Center for Health Security, Johns Hopkins University School of Public Health, Pratt Street, Baltimore, MD 21202, USA; jnuzzo1@jhu.edu

16 Cary Institute of Ecosystem Studies, Box AB Millbrook, NY 12545, USA; hanb@caryinstitute.org

17 Environmental, Health and Safety Office (EHSO), Emory University, 1762 Clifton Rd., Suite 1200, Atlanta, GA 30322, USA; patty.olinger@emory.edu

18 EcoHealth Alliance, 460 West 34th Street, New York, NY 10001, USA; karesh@ecohealthalliance.org

19 Practical One Health Solutions, LLC, New Market, MD 21774, USA; pohsolutions@gmail.com

20 Plum Island Animal Disease Center, Department of Homeland Security, Greenport, NY 11944, USA; jbarnabei87@gmail.com

21 Department of Medicine Infectious Disease, Georgetown University, 600 New Jersey Avenue, NW Washington, DC 20001, USA; daniel.lucey8@gmail.com

22 EpiLab, Infectious Disease Research Centre, School of Veterinary Science, Massey University, Private Bag, 11 222, Palmerston North 4442, New Zealand

* Correspondence: kberger@gryphonscientific.com (K.M.B.); d.t.s.hayman@massey.ac.nz (D.T.S.H.); Tel.: +1-240-485-2559 (K.M.B.); +64-06-951-6047 (D.T.S.H.)

+ Deceased, 17 January 2019. 


\begin{abstract}
The global burden of infectious diseases and the increased attention to natural, accidental, and deliberate biological threats has resulted in significant investment in infectious disease research. Translating the results of these studies to inform prevention, detection, and response efforts often can be challenging, especially if prior relationships and communications have not been established with decision-makers. Whatever scientific information is shared with decision-makers before, during, and after public health emergencies is highly dependent on the individuals or organizations who are communicating with policy-makers. This article briefly describes the landscape of stakeholders involved in information-sharing before and during emergencies. We identify critical gaps in translation of scientific expertise and results, and biosafety and biosecurity measures to public health policy and practice with a focus on One Health and zoonotic diseases. Finally, we conclude by exploring ways of improving communication and funding, both of which help to address the identified gaps. By leveraging existing scientific information (from both the natural and social sciences) in the public health decision-making process, large-scale outbreaks may be averted even in low-income countries.
\end{abstract}

Keywords: One Health; zoonoses; Ebola virus; emerging infectious diseases

\title{
1. Introduction
}

For decades, researchers have been studying infectious diseases affecting people, domestic and wild animals, and plants. Researchers have characterized emerging infectious diseases from viruses such as Human Immunodeficiency Virus (HIV) [1] and Severe Acute Respiratory Syndrome (SARS) coronavirus (CoV) [2,3], and bacteria such as Escherichia coli O104:H4 in Germany and France [4,5]. Approximately $75 \%$ of emerging pathogens have their origins in non-human reservoir hosts and are classic examples of zoonoses [6]. Furthermore, antimicrobial resistance among zoonotic diseases has become a significant health security challenge [7-9]. Combined with vaccine research and development $(R \& D)$ and immunization campaigns, scientific studies have contributed to the prevention or reduction of disease transmission globally [10-12]. Existing scientific knowledge and experience could be built upon to prevent or mitigate future outbreaks. However, under pressure to respond quickly to emerging outbreaks, decision-makers struggle to identify effective and relevant medical and non-medical public health response measures because they may not have available information about the causative agents, assessments of potential health and/or economic effects, effective biosafety and infection control measures, information about societally appropriate control measures, and ready risk communication measures for their constituents. Three primary types of gaps (data and models, safety and security, and cultural awareness) limit the translation of research findings in the decision-making process before, during, and after emergencies.

The 2014-2016 West-African Ebola virus disease (EVD) outbreak reinforced the concept that a major pathogen outbreak in one country can affect other countries throughout the region and world, and highlighted the aforementioned gaps in leveraging existing knowledge and practices to facilitate outbreak response $[13,14]$. This outbreak demonstrated that urban settings, socio-cultural traditions, and local migration affect outbreak dynamics. These lessons, along with the development and use of an experimental Ebola virus vaccine, contributed to very different responses in the 2018 outbreaks in the Democratic Republic of Congo (DRC) [15]. However, conflict and an unsafe public health response environment in the DRC towards the end of 2018 and into 2019 have led to a significant increase of known cases to over 1000 [16]. As long as the security situation ensues, the number of cases will continue to increase and the ability of researchers to collect information about circulating strains will be hampered.

In addition, advancing genomic sequencing capabilities are used to generate increasing amounts of data about bacteria, viruses, and other microorganisms in different locations. For example, the 
U.S. government has supported sequencing and modelling studies to identify different strains of pathogens in nature and evaluate their potential to initiate or drive outbreaks of local and international concern. The Canadian government, World Health Organization, U.S. government, non-governmental organizations (e.g., ProMED-mail), private companies, and research groups have leveraged data analytics platforms to analyze these and other available data and attempt to identify potential outbreaks before they become significant public health problems [17-20]. These platforms integrate epidemiological or syndromic data from a variety of sources, both official (e.g., Ministry of Health reports) and unofficial (e.g., media reports) sources, to help identify potential outbreaks as early as possible. The utility of these and related efforts relies on access to data, the sharing of which is governed by different international and national-level policies, and on awareness among policy-makers that scientific information, however uncertain, can inform initial and ongoing assessments of infectious disease risk and response [21,22]. These platforms do not appear to incorporate systematically the results from environmental scanning, modeling, and other related research fields. These platforms vary by the purpose, their intended stakeholders, the data they integrate, their analytic capabilities and methodologies, their accuracy, and other factors, all of which have different utility to public health decision-makers [23-25].

Although these results often are published in academic literature, decision-makers may not be aware that the studies exist, may not have access to the publication or the information contained therein, may not know how best to integrate the information into their decision-making processes, and/or may prefer to rely on scientific studies conducted by government, rather than non-governmental, researchers. Therefore, the existence of research, biosurveillance platforms, and official reporting mechanisms for infectious disease events does not necessarily indicate that these activities intersect and inform each other.

As observed after the launch of the 2014 Global Health Security Agenda (GHSA) and associated action packages, much of the scientific information accessed by human and animal health officials and public health decision-makers was, and continues to be, generated by local and/or central diagnostic laboratories [26-28]. Continuing to address gaps in these capabilities can lead to significant advances in disease prevention, such as a recent response to Nipah virus in India [29]. However, different sectors (specifically, academic, industry, and non-profit organizations) comprise the science and technology communities that develop and provide the tools necessary for detection, characterization, and analysis of infectious disease events. The results of this basic and applied research are published in scientific articles and discussed at scientific conferences, and genetic sequences and other similar information are deposited in databases, many of which exist for various model systems (e.g., plants and animals) and microbes. The scientists who conduct these studies become experts in their fields, often having the skills to help understand the significance of unusual outbreaks with known pathogens and to characterize new pathogens that resemble the ones they study. For example, in 2003, researchers on three continents who studied known respiratory pathogens were able to identify the first member of the coronavirus family causing widespread pneumonia in humans, the SARS-CoV [2,3,30-33]. In addition, researchers who study insects contribute to the scientific knowledge about how mosquitoes and ticks transmit pathogens such as Zika virus and Borrelia burgdorferi (the causative agent of Lyme disease), respectively. However, the expertise of the independent researchers (i.e., researchers who are not embedded within public or veterinary health agencies) and the data they produce often are not included in the decision-making process for outbreak response, unless prior relationships exist between the researchers and the public health decision-makers and practitioners.

The disconnect between research investment in human and animal health decision-making about infectious disease outbreaks and translation of data and expertise generated from research in the decision-making process may limit some early detection and response activities needed to prevent and control infectious disease outbreaks. This article describes the current state of scientific input in the public health decision-making process and highlights the different types of organizations involved in communicating scientific information before and during outbreaks. Based on the identified gaps, 
we consider approaches for promoting communication and trust-building between scientists (both governmental and non-governmental scientists) and policy-makers to ensure that existing data and knowledge can be brought to bear when preparing for, assessing, and responding to infectious disease incidents. Among these approaches, promoting objective, open communication among policy-makers and researchers (from the natural and social sciences) before, during, and after public health emergencies are critical for achieving the goals of the GHSA and related initiatives focused on reducing natural, accidental, and deliberate biological risks, frequently through the lens of One Heath.

\section{Science Informing Global Health Security Decision Making}

\section{Information Pathways and Decision-Making in Crises}

The flow of scientific information into the global health security decision-making process relies on several key factors, including: (a) networks of experts who are familiar to decision-makers and trusted experts in their respective fields; (b) information that is accessible to organizations and individuals involved in public health response; (c) decision-makers' ability to understand and evaluate scientific information; and (d) the use of scientific information by individual(s) responsible for assessing the public health situation and operational decisions. In this paper, we distinguish between scientific information (i.e., data) collected during an outbreak, and information generated by clinical or fundamental research prior to an outbreak and published in publicly-available literature, regardless of whether it is open access or available for a fee. In addition, we group together organizations involved in data generation, whether through research or epidemiological studies, which includes academic, industrial, non-profit, human and animal diagnostic, and government laboratories. We distinguish these scientists from public health decision-makers and practitioners, who play roles in policy-making and/or health response operations. All of these stakeholders are critical to the effective translation of data to public health emergency prevention, detection, and response.

Under non-emergency conditions, scientific and technical information usually is provided to policy and decision-makers of all levels (e.g., health and agricultural agencies, political leaders, and lawmakers) through a variety of means, including white papers, briefings, informal communication, published papers, and scientific conferences [34,35]. However, the flow of scientific information during emergencies is different, often reflecting the immediacy of the situation. The GHSA and International Health Regulations (IHR) provide a defined process, through guidance, for the generation and reporting of public health emergencies of potential international concern. No clear process exists for compiling and evaluating previously published scientific data to inform public health decision-making. Without trusted networks of experts and organizations that communicate scientific information to policy-makers objectively, interest groups which provide information selectively, may be the prevailing voice [36,37]. This situation may result in policy-makers developing trusted relationships with individuals and organizations with biases, which may limit objective and thorough examination of the human, animal, agricultural, or environmental health problem(s). At the same time, many researchers, though not all, do not engage with policy-makers because they do not believe they play a role in policy or decision-making and/or believe that decision-makers may not be willing to listen to their insights. This lack of engagement can limit the quality and objectivity of information being conveyed to decision-makers.

Limitations in effective translation of scientific information under emergency and non-emergency conditions determine its use in decision-making. For example, if information is perceived as partial (i.e., incomplete and/or highly uncertain) or people communicating the information are perceived as biased, decision-makers may question the utility of the data or disregard it completely. Similarly, data inconsistent with beliefs, traditions, or political agendas may be disregarded and/or discredited to maintain cultural and social realities. For example, a number of parents choose to not vaccinate their children for unsubstantiated reasons, including a disbelief in the necessity of the vaccines, perception that vaccines cause infections rather than prevent them, and belief that vaccines may cause 
autism [38]. Conversely, more complete data sets, more objective communication of the data, and clearer descriptions of the uncertainty of the data and analytic results may engender greater confidence in the information contributing to the decision-making process, especially if communicated effectively and appropriately for the audience.

In emergency situations, when timing and dynamics change, confidence in scientific information and advice is extremely important. Decision-makers frequently do not have time to identify and familiarize themselves with existing scientific information. Consequently, gaps in knowledge may develop, leading to uncertainty about the utility of scientific data. Similarly, uncertainty in known data also may lead decision-makers to question the utility of the scientific data. In addition, the process for sharing information with decision-makers may be cumbersome, inefficient, or nonexistent, all hampering scientifically-informed decision making. Although these limitations exist in non-emergency situations, they are exacerbated in emergencies. Therefore, during emergencies, decision-makers rely more on established relationships with experts for sourcing scientific information, which may include relevant knowledge and expertise (e.g., 2003 SARS-CoV outbreak) or only public health data, ignoring other sources (e.g., 2014-2016 West Africa EVD outbreak).

\section{Key Gaps and Impediments to Science-Driven Decision Making}

\subsection{Data and Models}

Incorporating social, natural, computational, and mathematical science analyses, including collection and characterization of specimens [39], into public health decision-making processes may help prevent future outbreaks of infectious diseases [40]. Full integration of information is difficult to achieve because of a lack of cross-pollination of disciplines and sectors [41]. Under-resourced individuals and organizations (including diagnostic and research laboratories, particularly in low-resource countries) may not have the capacity to conduct needed scientific assessments and communicate results to key audiences, which significantly limits the sharing and use of scientific information by researchers, health officials, and decision-makers. In addition, to evaluate the potential risk of emerging outbreaks, researchers and decision-makers must interpret new scientific findings from multidisciplinary studies and modeling data, which may vary in uncertainty based on the availability and veracity of the input data [42]. The relative lack of inter-disciplinary research and data analysis $[43,44]$ in research of public health relevance contributes to these challenges of data interpretation and risk assessment.

Scientific methodologies, such as ecological niche modeling and spatial regression analyses, could contribute to better situational awareness in public health crises [45-48]. Combining these analyses with existing case studies may improve outbreak prediction and prevention (e.g., recent assessments of mosquito vectors for Zika virus in the United States) [49]. These and other types of modeling approaches [50,51] help to identify the information needs for which little data exist by leveraging results from other studies and revealing key knowledge gaps that, if filled, could improve accuracy and reduce the uncertainty of computational models $[42,44,52,53]$. As data are generated and analytic capabilities improve, uncertainty associated with modeling and data analysis decreases. Therefore, investments in cross-disciplinary research on ecology, wildlife and domestic animals, human health, behavioral sciences, implementation science, and cultural anthropology are essential for understanding how humans interact with their environments and how these interactions facilitate the emergence of previously unknown, wildlife-derived pathogens in the human population [54-58]. Similar trends can be observed with integration of social and biomedical sciences research, where research on behavioral change can inform compliance with medical interventions [59-61]. Communicating these and other data clearly and concisely to public health decision-makers is important for translating research investments to public health practice [62]. 


\subsection{Safety and Security}

From a risk management and infection control perspective, data on the capability of nations to respond to emerging or re-emerging infectious disease events are incomplete and the local traditions that inform control measures generally are not integrated into formal public health responses [63-69]. However, these data play a key role in implementing measures that meet the objectives of the 2005 IHR, OIE (World Organization for Animal Health) Standards, and the GHSA objectives and Action Packages (https://ghsagenda.org/). In 2016, a Commission on a Global Health Risk Framework for the Future highlighted the neglected dimension of security in global health [70]. Still, the ability to protect scientists, healthcare providers, the community, and the environment from exposure to pathogens that could harm public health and safety often is overlooked. However, this situation may change through efforts such as the GHSA 2024 Framework [71].

Critical to successful outbreak prevention and management is recognizing the need to identify, test, and employ biosafety and biosecurity measures that are sustainable and adoptable in local conditions, account for local infrastructure, laws, and social structure, and prevent accidental and deliberate release of studied pathogens. Outbreak investigations for Ebola virus, Middle East Respiratory Syndrome coronavirus (MERS-CoV), and SARS-CoV demonstrated the need for locally effective biosafety measures that protect healthcare workers, diagnostic laboratory workers, and animal health workers from exposure to the outbreak viruses, and biosecurity measures that prevent access to pathogens by malicious actors. Applied research may identify measures that enhance current risk management efforts, such as laboratory and clinical biosafety, biosecurity, and biorisk management.

\subsection{Cultural Awareness}

Social science research can provide a better understanding of local culture and traditions, which strongly influence pathogen transmission and acceptance of medical and public health interventions [43]. During the 2014-2016 West African EVD outbreak, a lack of cultural awareness about local end-of-life traditions led to ineffective or unintentionally dangerous public health interactions and undocumented infections [72-74]. Eventually, the public health community began identifying approaches to communicate the risk of virus transmission from touching infected bodies, mitigate transmission events through culturally acceptable means, and reduce fear of death through appropriately chosen infection control methods (e.g., use of white, instead of black, body bags in West Africa [75]). Early engagement with communities and social scientists who study the culture, tradition, and linguistics of people from affected areas would help inform communication by decision-makers, mitigation strategies used by public health responders, and trust-building with the local population. Furthermore, leveraging the knowledge gained from these social science disciplines could enhance efforts to build trust among affected individuals rather than allow the persistence of distrust between local communities and foreign health workers [76,77]. Similar approaches should be used towards domestic and wild animal research, with animal and conservation ethics and local cultural and traditions considered.

Research involving bioethics and social equity helps scientists incorporate ethical principles in the design and conduct studies involving human participants affected by public health emergencies [78]. Such studies are critically important for research examining the effectiveness of candidate vaccines and medicines, understanding pathogen transmission and infection in natural settings, and testing non-pharmaceutical interventions for disease prevention and mitigation. Although such studies have been conducted for years, the U.S. National Academies of Science, Engineering, and Medicine highlighted research needs for preparedness and response to public health emergencies and associated bioethical considerations [79]. This focus on the bioethics of disaster research has prompted non-governmental and governmental organizations alike to evaluate challenges and identify solutions to promote ethical practices in research during public health emergencies. Building on this and other social science research can promote the development and implementation of clinical and public health research that takes into account the culture, society, and benefits to and needs of research participants. 


\section{Potential Solutions}

The purpose of much of infectious disease research is to identify pharmaceutical and non-pharmaceutical approaches for preventing, detecting and monitoring, and responding to public health outbreaks of national, regional, and international concern. Data that could inform prevention, detection, and response activities are generated by several different types of studies, including mathematical modeling, epidemiological studies, environmental scanning, life-sciences studies (e.g., microbial genomics), and cultural anthropology. By integrating known, published data in these fields, considering key knowledge gaps and existing areas of uncertainty, scientists can assist public health responders and decision-makers in understanding initial cases and feasible infection control measures. However, the results of these investments have limited utility if they are not being conveyed to policy-makers before the occurrence of and during an emergency. Without this information, human and animal health officials and health care professionals are left to diagnose emerging outbreaks using sub-optimal approaches and driving response efforts that might be unnecessarily ineffective and promulgating distrust in health response efforts.

Three approaches for addressing these gaps are communication, funding, and translation efforts. Although not explicitly described in this paper, international and national policies on data access and decisions made for political or national security purposes present additional challenges to fully informed decision-making. Some of the solutions described in this section may help reduce, but not eliminate, these challenges, highlighting the realities inherent in global governance of public health preparedness and response. Nevertheless, the proposed solutions could improve communication between researchers and decision-makers and enhance translation of research investments to inform public health practice before, during, and after emergencies.

\subsection{Communication}

Communication strategies that include better articulation and dissemination of existing scientific knowledge and modeling approaches (including their use, gaps, and limitations), their relevance to public health emergencies, and the inherent uncertainties in scientific assessment greatly would enhance high-level public health decision-making before, during, and after emergencies [34]. Better awareness about the types of public health decisions, associated information needs, operational constraints, time pressures of decision-makers, and limitations of current scientific knowledge would enable researchers to communicate scientific information more effectively. Understanding what is required of data and how data are best communicated in public health emergencies would provide researchers with the necessary operational context in which decision-makers must evaluate and base their decisions. With greater appreciation for the limitations of and information needs during the decision-making process, researchers can identify, integrate and distill data of greatest relevance to the specific emergency.

Effective communication can be achieved through active interaction or written documents, and fostered in a variety of venues, including scientific conferences, science and society workshops, and governmental meetings. Although some of these efforts currently are used, their effectiveness can be improved by tailoring communication to the audience. Interactions cultivated among stakeholders before emergencies could promote the development of trusted relationships between decision-makers and scientists, which can serve as the foundation for reach-back during public health emergencies. In addition, interactions through networks, such as the GHSA and associated groups, could promote open lines of communication between governmental health security officials and scientists, facilitating information-sharing and enabling greater understanding of key questions with which decision-makers struggle [35]. These interactions are most effective if they are in place before crises occur and maintained after an emergency ends, which can lead to greater trust and familiarity between policy-makers and researchers and more opportunities for information-sharing in non-emergency situations. Throughout, promoting diversity of scientific expertise and experiences within these communications networks is 
critical for ensuring that policy-makers receive unbiased, objective information upon which to base their decisions.

\subsection{Funding and Open Access}

Research investments can enhance detection, characterization, assessment, and response to infectious diseases. However, several challenges exist with the current approaches: (1) limited funding is available for basic research for a majority of infectious diseases, particularly neglected tropical diseases and wildlife-associated, epizootic (animal only) diseases; (2) limited funding opportunities exist for multi-disciplinary, multi-sectoral research and education; (3) limited support is provided for social science research that is relevant to prevention and mitigation of infectious disease outbreaks; (4) research funding continuously changes for many infectious diseases, limiting the sustainability of individual efforts (e.g., the 2018 U.S. President's proposed budget included funding cuts for efforts to prevent and respond to EVD outbreaks even as the 2018 outbreak in the DRC emerged [80,81]); (5) lack of communication from scientists to non-technical audiences, including policy-makers; and (6) lack of evaluation metrics for assessing the effectiveness of scientific input into the public health process.

To counter these challenges, government agencies, intergovernmental organizations, private funders, and philanthropic organizations should develop forward-looking, longer-term initiatives that support basic and applied research in a variety of natural and social sciences, and in efforts promoting integration and translation of scientific data to public health emergency prevention, detection, and response. Although not routinely done, proactive and stable funding for these and other scientific inquiries provides opportunities to increase the knowledge-base from which decision-makers can draw when considering appropriate infection control actions, a suggestion supported by several scientific organizations. For example, longer-term studies, such as those on New World hantaviruses, have produced a great deal of information relevant to public health [82], including changing infection prevalence with species richness [83], the preponderance of infected males [84], and the role of climatic changes in causing fluctuations in rodent reservoir populations and their links to localized, sporadic disease outbreaks. Although these studies were initiated as part of a reactive response to an acute outbreak-in this case, hantavirus pulmonary syndrome-in 1993-1994, the information produced addresses key knowledge gaps that can inform future outbreaks. Similarly, research supported during and after EVD outbreaks has generated data on wildlife reservoir hosts and people's perceptions of health and healthcare practices, both of which could inform future outbreak assessments and response efforts. In addition, funders should establish a process through which the results and assessments can be communicated to public health decision-makers, leveraging the recent movement towards open access publication requirements. As a positive example, the Bill and Melinda Gates Foundation and The Wellcome Trust require all grantees to make their results publicly available, enabling access to various stakeholders, including decision-makers [85-87]. However, access to information does not ensure their use by decision-makers. In addition, new data protection laws may counteract these open access policies of funders and journals [88].

Specific approaches for promoting greater translation of research include scientific staff support for decision-makers, fellowship opportunities, cross-disciplinary cooperation, and strategic funding mechanisms (e.g., contracts and cooperative agreements). Scientists and funders should identify and support the integration and translation of science from multiple sectors, fields, and disciplines to identify key information gaps for global health security and provide the scientific foundation for assessing infectious disease risks. Funding support for training and fellowships can promote explicit scientific input into decision-making and encourage open sharing of data with other researchers and health officials. Researchers and research institutions should aim to shift the culture of data sharing by promoting the open sharing of data with public health practitioners as an academic product on par with publications, decreasing the potential for politicization or biased use of data [70]. Data sharing has been raised with H5N1 influenza A virus, Ebola virus, and Zika virus [89], and informed by efforts to promote equitable benefit of results from the sharing of data and 
samples from emerging outbreaks [90,91]. In 2014, the U.S. government passed the DATA (Data Transparency and Accountability) Act, which requires that data from federally-funded efforts be made open and available. The U.S. government's DATA.gov website (https://www.data.gov/) is the platform that was developed to store and provide access to the datasets. In addition, agencies such as U.S. Geological Survey now have an 'eternal data' archive called Science Base (https://www.sciencebase.gov/catalog/). Despite these efforts, national policies restricting data access and sharing to foreign entities present new challenges to equitable and reciprocal data sharing, especially as biological research increasingly relies on data science approaches [92].

Approaches for improving communication between researchers and policy-makers, the funding landscape, and open access policies could help promote research that addresses key knowledge gaps in health security policy and practice, and translate funded research to global health decision-making.

\subsection{Translation of Data}

Looking forward, the 2024 Framework of the Global Health Security Agenda stresses communication, political and financial advocacy, and engagement of a more diverse set of stakeholders [71]. In part, these efforts intend to increase national-level investment and support for addressing shortcomings in human and animal health capabilities that currently limit effective prevention, detection, and response to public health emergencies of international concern. However, the new structure developed to progress towards these GHSA efforts could be enhanced further by including the research community as a critical stakeholder and focusing attention on data sharing among the research, public health, veterinary health, agriculture, and environmental health communities. Active engagement of the scientific arms of research and diagnostic entities (regardless of their sector, whether academic, industry, or government laboratories) with local and national public and veterinary health entities could enable better translation of scientific information to address public health needs. Recent calls for integrating veterinary and human health research to improve One Health efforts, including policy development and implementation, have been published [93,94]. Training on and implementation of data translation, improved strategies for communicating data and their associated limitations and/or statistical significance, and active participation of the scientific community in public health decision-making processes could reveal opportunities for leveraging data in an informative and timely manner.

\section{Conclusions}

The global burden of infectious diseases and the increased attention to natural, accidental, and deliberate biological threats has resulted in scientific and financial investment in infectious disease research. However, the results of these studies often are not translated to prevention, detection, and response efforts. Furthermore, the needs, receptivity, and stakeholders involved in sharing scientific data before and during emergencies differ, which can lead to barriers towards research translation to human and animal health practice. Overcoming these barriers is necessary to prevent and mitigate emerging and re-emerging infectious diseases, including the recent epidemics caused by Zika virus in the Americas, Yellow fever virus (YFV) in Angola and the DRC, and Ebola virus in the DRC. The public health burden caused by influenza virus has led to the creation of WHO collaborating centers through which data on naturally circulating strains and results from basic and applied research are shared, informing influenza surveillance efforts. In addition, scientific data associated with the Zika virus disease outbreak has been placed in the public domain to facilitate prevention and control of the outbreak. However, these data sharing efforts are inconsistent across outbreaks, as demonstrated by the lack of similar data sharing practice in the YFV outbreak in Africa [95]. Furthermore, sharing of data is not the same as effective communication of the data.

Despite the increased investment for infectious disease research, significant knowledge gaps remain in host-pathogen interactions, urbanization and climactic influences on pathogen transmission, pathogen evolution, interactions between wild and domestic animals and humans, existence of 
unknown but naturally occurring pathogens, and other areas of interest. These knowledge gaps introduce uncertainty about what can be concluded from available data, which in turn can raise doubt in the utility of research results and validity of science-based conclusions during decision-making, especially in emergency situations. Advanced engagement and communication between researchers and policy-makers could help identify critical knowledge gaps that could reduce uncertainty levels and promote better trust between scientists and decision-makers. Encouraging and training scientists to recognize and translate research findings to public health decision-makers enhances these efforts. Effective communication and long-term funding are important for providing decision-makers with a clear understanding of what is known and what needs to be determined to improve prevention, detection, and response efforts of current and future outbreaks.

Author Contributions: Conceptualization, all authors; Writing-Original Draft preparation, K.M.B. and D.T.S.H.; Writing-Review and Editing, all authors.

Funding: DTSH is funded by Royal Society Te Apārangi, grant number MAU1701 and MAU1503. SSM is funded by the Arts and Letters Foundation.

Acknowledgments: The driver for this paper and its broad authorship was a workshop held in June 2015, titled "Joint RAPIDD-GHSA Workshop: Policy Implications of Detecting Hemorrhagic Fever Viruses in Wildlife and Domestic Animals". The workshop was held under the auspices of the National Institutes of Health and Department of Homeland Security-funded Research and Policy for Infectious Disease Dynamics (RAPIDD) program and in coordination with the U.S. Department of State. We thank Audrey Thevenon (National Academy of Sciences, Engineering, and Medicine), Rocco Casagrande (Gryphon Scientific), Christopher Hofmann (U.S. Department of State), Ellis McKenzie (National Institutes of Health, sadly deceased), and Bryan Grenfell (Princeton University) for their support.

Conflicts of Interest: The authors declare no conflict of interest. The funders had no role in the design of the study; in the collection, analyses, or interpretation of data; in the writing of the manuscript; or in the decision to publish the results. The findings and conclusions in this publication have not been formally disseminated by the U.S. Department of Agriculture and should not be construed to represent any agency determination or policy. Any use of trade product or firm names is for descriptive purposes only and does not imply endorsement by the U.S. Government or the authors.

\section{References}

1. Barré-Sinoussi, F.; Chermann, J.-C.; Rey, F.; Nugeyre, M.T.; Chamaret, S.; Gruest, J.; Dauguet, C.; Axler-Blin, C.; Vézinet-Brun, F.; Rouzioux, C. Isolation of a T-lymphotropic retrovirus from a patient at risk for acquired immune deficiency syndrome (AIDS). Science 1983, 220, 868-871. [CrossRef]

2. Rota, P.A.; Oberste, M.S.; Monroe, S.S.; Nix, W.A.; Campagnoli, R.; Icenogle, J.P.; Peñaranda, S.; Bankamp, B.; Maher, K.; Chen, M.-H.; et al. Characterization of a novel coronavirus associated with severe acute respiratory syndrome. Science 2003, 300, 1394-1399. [CrossRef] [PubMed]

3. Peiris, J.S.M.; Lai, S.T.; Poon, L.L.M.; Guan, Y.; Yam, L.Y.C.; Lim, W.; Nicholls, J.; Yee, W.K.S.; Yan, W.W.; Cheung, M.T.; et al. Coronavirus as a possible cause of severe acute respiratory syndrome. Lancet 2003, 361, 1319-1325. [CrossRef]

4. Rohde, H.; Qin, J.; Cui, Y.; Li, D.; Loman, N.J.; Hentschke, M.; Chen, W.; Pu, F.; Peng, Y.; Li, J.; et al. Open-source genomic analysis of shiga-toxin-producing E. coli O104:H4. N. Engl. J. Med. 2011, 365, 718-724. [CrossRef]

5. Frank, C.; Faber, M.; Askar, M.; Bernard, H.; Fruth, A.; Gilsdorf, A.; Höhle, M.; Karch, H.; Krause, G.; Prager, R. Large and ongoing outbreak of haemolytic uraemic syndrome. Euro Surveill. 2011, 16, 19878. [PubMed]

6. Taylor, L.H.; Latham, S.M.; Woolhouse, M.E. Risk factors for human disease emergence. Philos. Trans. R. Soc. Lond. Ser. B Biol. Sci. 2001, 356, 983-989. [CrossRef]

7. World Health Organization. Antimicrobial Resistance. Available online: https://www.who.int/en/newsroom/fact-sheets / detail/antimicrobial-resistance (accessed on 31 March 2019).

8. Asokan, G.V.; Kasimanickam, R.K. Emerging infectious diseases, antimicrobial resistance and millennium development goals: Resolving the challenges through one health. Cen. Asian J. Glob. Health 2013, 2, 76. [CrossRef] 
9. European Centre for Disease Prevention and Control. Zoonoses: Antimicrobial Resistance Shows no Signs of Slowing Down. Available online: https://ecdc.europa.eu/en/news-events/zoonoses-antimicrobialresistance-shows-no-signs-slowing-down (accessed on 31 March 2019).

10. Greenwood, B. The contribution of vaccination to global health: Past, present and future. Philos. Trans. $R$. Soc. Lond. B Biol. Sci. 2014, 369, 20130433. [CrossRef]

11. Francis, D.P. Success and failures: Worldwide vaccine development and application. Biologicals 2010, 38, 523-528. [CrossRef]

12. Greenwood, B.; Salisbury, D.; Hill, A.V.S. Vaccines and global health. Philos. Trans. R. Soc. Lond. B Biol. Sci. 2011, 366, 2733-2742. [CrossRef] [PubMed]

13. Heymann, D.L.; Chen, L.; Takemi, K.; Fidler, D.P. Global health security: The wider lessons from the West African Ebola virus disease epidemic. Lancet 2015, 385, 1884-1901. [CrossRef]

14. Backer, J.A.; Wallinga, J. Spatiotemporal analysis of the 2014 Ebola epidemic in West Africa. PLoS Comput. Biol. 2016, 12, e1005210. [CrossRef]

15. World Health Organization. Ebola Vaccine Provides Protection and Hope for High-Risk Communities in the Democratic Republic of the Congo. Available online: http:/ / www.who.int/news-room/feature-stories / detail/ebola-vaccine-provides-protection-and-hope-for-high-risk-communities-in-the-democraticrepublic-of-the-congo (accessed on 14 August 2018).

16. Centers for Disease Control and Prevention. Ebola Outbreak in Eastern Democratic Republic of Congo tops 1000 cases. Available online: https:/ / www.cdc.gov/media/releases/2019/s0322-ebola-congo.html (accessed on 31 March 2019).

17. Pellerin, C. DTRA Scientists Develop Cloud-Based Biosurveillance Ecosystem. Available online: https: / / dod.defense.gov /News / Article/Article/681832/dtra-scientists-develop-cloud-basedbiosurveillance-ecosystem/ (accessed on 17 March 2019).

18. Public Health Agency of Canada. About GPHIN. Available online: https://gphin.canada.ca/cepr/ aboutgphin-rmispenbref.jsp?language=en_CA (accessed on 14 August 2018).

19. World Health Organization. Global Outbreak Alert and Response Network (GOARN). Available online: http:/ / www.who.int/ihr/alert_and_response/outbreak-network/en/ (accessed on 14 August 2018).

20. ProMED. International Society for Infectious Diseases. Available online: http://www.promedmail.org/ (accessed on 14 February 2019).

21. Holmes, E.C.; Rambaut, A.; Andersen, K.G. Pandemics: spend on surveillance, not prediction. Nature 2018, 558, 180-182. [CrossRef]

22. Rivers, C.; Scarpino, S. Modelling the trajectory of disease outbreaks works. Nature 2018, 559, 477. [CrossRef]

23. Milinovich, G.J.; Soares Magalhaes, R.J.; Hu, W. Role of big data in the early detection of Ebola and other emerging infectious disease. Lancet Glob. Health 2015, 3, PE20-PE21. [CrossRef]

24. Lazer, D.; Kennedy, R.; King, G.; Vespignani, A. The parable of google flu: Traps in big data analysis. Science 2014, 343, 1203-1205. [CrossRef]

25. Dion, M.; AbdelMalik, P.; Mawudeku, A. Big data and the global public health intelligence network (GPHIN). Can. Commun. Dis. Rep. 2015, 41, 209-214. [CrossRef]

26. Kennedy, E.D.; Morgan, J.; Knight, N.W. Global health security implementation: Expanding the evidence base. Health Security 2018. [CrossRef]

27. Edelson, M.; Lee, L.M.; Herten-Crabb, A.; Heymann, D.L.; Harper, D.R. Strengthening global public health surveillance through data and benefit sharing. Emerg. Infect. Dis. 2018, 24, 1324-1330. [CrossRef]

28. Rodier, G.; Greenspan, A.L.; Hughes, J.M.; Haymann, D.L. Global public health security. Emerg. Infect. Dis. 2007, 13, 1447-1452. [CrossRef]

29. Sadanadan, R.; Arunkumar, G.; Laserson, K.F.; Heretik, K.H.; Singh, S.; Mourya, D.T.; Gangakhedkar, R.R.; Gupta, N.; Sharma, R.; Dhuria, M. Towards global health security: Response to the May 2018 Nipah virus outbreak linked to pteropus bats in Kerala, India. BMJ Glob. Health 2018, 3, e001086. [CrossRef]

30. Fouchier, R.A.M.; Kuiken, T.; Schutten, M.; van Amerongen, G.; van Doornum, G.J.J.; van den Hoogen, B.G.; Peiris, M.; Lim, W.; Stöhr, K.; Osterhaus, A.D.M.E. Koch's postulates fulfilled for SARS virus. Nature 2003, 423, 240. [CrossRef]

31. Drosten, C.; Günther, S.; Preiser, W.; Van Der Werf, S.; Brodt, H.-R.; Becker, S.; Rabenau, H.; Panning, M.; Kolesnikova, L.; Fouchier, R.A. Identification of a novel coronavirus in patients with severe acute respiratory syndrome. N. Eng. J. Med. 2003, 348, 1967-1976. [CrossRef] 
32. Falsey, A.R.; Walsh, E.E. Novel coronavirus and severe acute respiratory syndrome. Lancet 2003, 361, 1312-1313. [CrossRef]

33. Ksiazek, T.G.; Erdman, D.; Goldsmith, C.S.; Zaki, S.R.; Peret, T.; Emery, S.; Tong, S.; Urbani, C.; Comer, J.A.; Lim, W. A novel coronavirus associated with severe acute respiratory syndrome. N. Eng. J. Med. 2003, 348, 1953-1966. [CrossRef]

34. Whitty, C.J. What makes an academic paper useful for health policy? BMC Med. 2015, 13, 1. [CrossRef]

35. Cook, C.N.; Mascia, M.B.; Schwartz, M.W.; Possingham, H.P.; Fuller, R.A. Achieving conservation science that bridges the knowledge-action boundary. Conserv. Biol. 2013, 27, 669-678. [CrossRef]

36. Contandriopoulos, D.; Brousselle, A.; Brenton, M.; Larouche, C.; Champagne, G.; Rivard, G. Policy-making: polarization and interest group influence: Damien Contradriopoulos. Eur. J. Public Health 2017, 27 (Suppl. 3). [CrossRef]

37. Kushel, M.; Bindman, A.B. Healthcare lobbying: Time to make patients the special interest. Am. J. Med. 2004, 116, 496-497. [CrossRef]

38. World Health Organization. Global Vaccine Safety. Available online: https://www.who.int/vaccine_safety/ initiative/detection/immunization_misconceptions/en/ (accessed on 8 February 2018).

39. DiEuliis, D.; Johnson, K.R.; Morse, S.S.; Schindel, D.E. Opinion: Specimen collections should have a much bigger role in infectious disease research and response. Proc. Natl. Acad. Sci. USA 2016, 113, 4-7. [CrossRef]

40. Morse, S.S.; Mazet, J.A.; Woolhouse, M.; Parrish, C.R.; Carroll, D.; Karesh, W.B.; Zambrana-Torrelio, C.; Lipkin, W.I.; Daszak, P. Prediction and prevention of the next pandemic zoonosis. Lancet 2012, 380, 1956-1965. [CrossRef]

41. Manlove, K.R.; Walker, J.G.; Craft, M.E.; Huyvaert, K.P.; Joseph, M.B.; Miller, R.S.; Nol, P.; Patyk, K.A.; O'Brien, D.; Walsh, D.P. “One Health” or three? Publication silos among the one health disciplines. PLoS Biol. 2016, 14, e1002448. [CrossRef]

42. Chretien, J.-P.; Riley, S.; George, D.B. Mathematical modeling of the West Africa Ebola epidemic. eLife 2015, 4, e09186. [CrossRef]

43. Wood, J.L.; Leach, M.; Waldman, L.; Macgregor, H.; Fooks, A.R.; Jones, K.E.; Restif, O.; Dechmann, D.; Hayman, D.T.; Baker, K.S.; et al. A framework for the study of zoonotic disease emergence and its drivers: Spillover of bat pathogens as a case study. Philos. Trans. R. Soc. Lond. Ser. B Biol. Sci. 2012, 367, 2881-2892. [CrossRef]

44. Restif, O.; Hayman, D.T.; Pulliam, J.R.; Plowright, R.K.; George, D.B.; Luis, A.D.; Cunningham, A.A.; Bowen, R.A.; Fooks, A.R.; O'Shea, T.J. Model-guided fieldwork: practical guidelines for multidisciplinary research on wildlife ecological and epidemiological dynamics. Ecol. Lett. 2012, 15, 1083-1094. [CrossRef]

45. Brierley, L.; Vonhof, M.J.; Olival, K.J.; Daszak, P.; Jones, K.E. Quantifying global drivers of zoonotic bat viruses: A process-based perspective. Am. Nat. 2016, 187, E53-E64. [CrossRef]

46. Pigott, D.M.; Golding, N.; Mylne, A.; Huang, Z.; Henry, A.J.; Weiss, D.J.; Brady, O.J.; Kraemer, M.U.; Smith, D.L.; Moyes, C.L. Mapping the zoonotic niche of Ebola virus disease in Africa. eLife 2014, 3, e04395. [CrossRef]

47. Pigott, D.M.; Golding, N.; Mylne, A.; Huang, Z.; Weiss, D.J.; Brady, O.J.; Kraemer, M.U.; Hay, S.I. Mapping the zoonotic niche of Marburg virus disease in Africa. Trans. R. Soc. Trop. Med. Hyg. 2015, 109, 366-378. [CrossRef]

48. Peterson, A.; Bauer, J.; Mills, J. Ecologic and geographic distribution of filovirus disease. Emerg. Infect. Dis. 2004, 10, 40-47. [CrossRef]

49. Monaghan, A.J.; Morin, C.W.; Steinhoff, D.F.; Wilhelmi, O.; Hayden, M.; Quattrochi, D.A.; Reiskind, M.; Lloyd, A.L.; Smith, K.; Schmidt, C.A. On the seasonal occurrence and abundance of the Zika virus vector mosquito Aedes aegypti in the contiguous United States. PLoS Curr. 2016, 8. [CrossRef]

50. Han, B.A.; Schmidt, J.P.; Alexander, L.; Bowden, S.E.; Hayman, D.T.S.; Drake, J.M. Undiscovered bat hosts of filoviruses. PLoS Negl. Trop. Dis. 2016, 10, e0004815. [CrossRef]

51. Hayman, D.T. Biannual birth pulses allow filoviruses to persist in bat populations. Proc. R. Soc. Lond. B Biol. Sci. 2015, 282, 20142591. [CrossRef]

52. King, A.A.; de Cellès, M.D.; Magpantay, F.M.; Rohani, P. Avoidable errors in the modelling of outbreaks of emerging pathogens, with special reference to Ebola. Proc. R. Soc. Lond. B Biol. Sci. 2015, 282, 20150347. [CrossRef] 
53. Plowright, R.K.; Eby, P.; Hudson, P.J.; Smith, I.L.; Westcott, D.; Bryden, W.L.; Middleton, D.; Reid, P.A.; McFarlane, R.A.; Martin, G. Ecological dynamics of emerging bat virus spillover. Proc. R. Soc. Lond. B Biol. Sci. 2015, 282, 20142124. [CrossRef]

54. Calvignac-Spencer, S.; Leendertz, S.; Gillespie, T.; Leendertz, F. Wild great apes as sentinels and sources of infectious disease. Clin. Microbiol. Infect. 2012, 18, 521-527. [CrossRef]

55. Gillespie, T.R.; Nunn, C.L.; Leendertz, F.H. Integrative approaches to the study of primate infectious disease: Implications for biodiversity conservation and global health. Am. J. Phys. Anthropol. 2008, 137, 53-69. [CrossRef]

56. Anti, P.; Owusu, M.; Agbenyega, O.; Annan, A.; Badu, E.K.; Nkrumah, E.E.; Tschapka, M.; Oppong, S.; Adu-Sarkodie, Y.; Drosten, C. Human-bat interactions in rural West Africa. Emerg. Infect. Dis. 2015, 21, 1418-1421. [CrossRef]

57. Kamins, A.O.; Restif, O.; Ntiamoa-Baidu, Y.; Suu-Ire, R.; Hayman, D.T.; Cunningham, A.A.; Wood, J.L.; Rowcliffe, J.M. Uncovering the fruit bat bushmeat commodity chain and the true extent of fruit bat hunting in Ghana, West Africa. Biol. Conserv. 2011, 144, 3000-3008. [CrossRef]

58. Kamins, A.O.; Rowcliffe, J.M.; Ntiamoa-Baidu, Y.; Cunningham, A.A.; Wood, J.L.; Restif, O. Characteristics and risk perceptions of Ghanaians potentially exposed to bat-borne zoonoses through bushmeat. EcoHealth 2014, 12, 104-120. [CrossRef]

59. Kippax, S. Understanding and integrating the structural and biomedical determinants of HIV infection: A way forward for prevention. Curr. Opin. HIV AIDS 2008, 3, 489-494. [CrossRef]

60. Mabry, P.L.; Olster, D.H.; Morgan, G.D.; Abrams, D.B. Interdisciplinarity and systems science to improve population health: A view from the NIH office of behavioral and social sciences research. Am. J. Prev. Med. 2008, 35, S211-S224. [CrossRef]

61. Jin, J.; Sklar, G.E.; Oh, V.M.S.; Li, S.C. Factors affecting therapeutic compliance: A review from the patient's perspective. Ther. Clin. Risk Manag. 2008, 4, 269.

62. Ogilvie, D.; Craig, P.; Griffin, S.; Macintyre, S.; Wareham, N.J. A translational framework for public health research. BMC Public Health 2009, 9, 116. [CrossRef]

63. Jephcott, F.L.; Wood, J.L.; Cunningham, A.A. Facility-based surveillance for emerging infectious diseases; diagnostic practices in rural West African hospital settings: Observations from Ghana. Phil. Trans. R. Soc. B 2017, 372, 20160544. [CrossRef]

64. Manguvo, A.; Mafuvadze, B. The impact of traditional and religious practices on the spread of Ebola in West Africa: Time for a strategic shift. Pan. Afr. Med. J. 2015, 22 (Suppl. 1), 9.

65. Carrion Martin, A.I.; Derrough, T.; Honomou, P.; Kolie, N.; Diallo, B.; Kone, M.; Rodier, G.; Kpoghomou, C.; Jansa, J.M. Social and cultural factors behind community resistance during an Ebola outbreak in a village of the Guinean Forest region, February 2015: A field experience. Int. Health 2016, 8, 227-229. [CrossRef]

66. Ulin, P.R. African women and AIDS: Negotiating behavioral change. Soc. Sci. Med. 1992, 34, 63-73. [CrossRef]

67. De Bruym, M. Women and aids in developing countries: The XIIth international conference on the social sciences and medicine. Soc. Sci. Med. 1992, 34, 249-262. [CrossRef]

68. Ventura-Garcia, L.; Roura, M.; Rell, C.; Posada, E.; Gascon, J.; Aldasoro, E.; Munoz, J.; Pool, R. Socio-cultural aspects of chagas disease: A systematic review of qualitative research. PLoS Negl. Trop. Dis. 2013, 7, e2410. [CrossRef]

69. Richards, P.; Amara, J.; Ferme, M.C.; Mokuwa, E.; Sheriff, A.I.; Suluku, R.; Voors, M. Social pathways for Ebola virus disease in rural Sierra Leone, and some implications for containment. PLoS Negl. Trop. Dis. 2015, 9, e0003567. [CrossRef]

70. Sands, P.; Mundaca-Shah, C.; Dzau, V.J. The neglected dimension of global security-A framework for countering infectious-disease crises. N. Eng. J. Med. 2016, 374, 1281-1287. [CrossRef]

71. Global Health Security Agenda. 2024 Framework. Available online: https://www.ghsagenda.org/docs / default-source/default-document-library/ghsa-2024-files / ghsa-2024-framework.pdf?sfvrsn=4 (accessed on 30 March 2019).

72. Spengler, J.R.; Ervin, E.D.; Towner, J.S.; Rollin, P.E.; Nichol, S.T. Perspectives on West Africa Ebola virus disease outbreak, 2013-2016. Emerg. Infect. Dis. 2016, 22, 956-963. [CrossRef] 
73. Pandey, A.; Atkins, K.E.; Medlock, J.; Wenzel, N.; Townsend, J.P.; Childs, J.E.; Nyenswah, T.G.; Ndeffo-Mbah, M.L.; Galvani, A.P. Strategies for containing Ebola in West Africa. Science 2014, 346, 991-995. [CrossRef]

74. World Health Organization. Factors that Contributed to Undetected Spread of the Ebola Virus and Impeded Rapid Containment; WHO: Geneva, Switzerland, 2015; Available online: https:/ /www.who.int/csr/disease/ebola/ one-year-report/factors/en/ (accessed on 17 March 2019).

75. DuBois, M.; Wake, C.; Sturridge, S.; Bennett, C. The Ebola response in West Africa: Exposing the Politics and Culture of International Aid. Available online: http:/ / www.odi.org/publications/9936-ebola-responsewest-africa-exposing-politics-culture-international-aid (accessed on 14 February 2019).

76. AlJezeera America. Saudi Arabia Announces 92 more MERS deaths, Sacks Deputy Health Minister. Available online: http:/ / america.aljazeera.com/articles/2014/6/3/saudi-raises-mersdeathtollandcases. html (accessed on 17 March 2018).

77. The Guardian. China Accused of SARS Cover-up. Available online: http://www.theguardian.com/world/ 2003/apr/09/sars.china (accessed on 17 March 2019).

78. Convention on Biological Diversity. Nagoya Protocol. Available online: https://www.cbd.int/abs/about/ (accessed on 17 March 2019).

79. Institute of Medicine. Enabling Rapid and Sustainable Public Health Research During Disasters: Summary of a Joint Workshop by the Institute of Medicine and the U.S. Department of Health and Human Services; The National Academies Press: Washington, DC, USA, 2015; p. 190. [CrossRef]

80. Garrett, L. Ebola is back. And Trump is trying to kill funding for it. Available online: https:/ / foreignpolicy. com/2018/05/09/ebola-is-back-and-trump-is-trying-to-kill-funding-for-it/ (accessed on 17 March 2019).

81. Kaiser Family Foundation. Trump administration requests rescission of \$252M in 2015 Ebola funds as Congo addresses new outbreak. Available online: https:/ / www.kff.org/news-summary/trump-administrationrequests-rescission-of-252m-in-2015-ebola-funds-as-congo-addresses-new-outbreak/ (accessed on 17 March 2019).

82. Mills, J.N.; Ksiazek, T.G.; Peters, C.; Childs, J.E. Long-term studies of hantavirus reservoir populations in the southwestern United States: A synthesis. Emerg. Infect. Dis. 1999, 5, 135. [CrossRef]

83. Luis, A.D.; Kuenzi, A.J.; Mills, J.N. Species diversity concurrently dilutes and amplifies transmission in a zoonotic host-pathogen system through competing mechanisms. Proc. Natl. Acad. Sci. USA 2018, 115, 7979-7984. [CrossRef]

84. Luis, A.D.; Douglass, R.J.; Hudson, P.J.; Mills, J.N.; Bjørnstad, O.N. Sin nombre hantavirus decreases survival of male deer mice. Oecologia 2012, 169, 431-439. [CrossRef]

85. Bill and Melinda Gates Foundation. How We Work: Information Sharing Approach. Available online: https:/ / www.gatesfoundation.org/How-We-Work/General-Information/Information-SharingApproach (accessed on 12 June 2018).

86. Bill and Melinda Gates Foundation. How we work: Open Access Policy. Available online: https: / / www. gatesfoundation.org/how-we-work/general-information/open-access-policy (accessed on 17 March 2019).

87. Wellcome Trust. Open Access Policy. Available online: https://wellcome.ac.uk/funding/managing-grant/ open-access-policy (accessed on 2 February 2018).

88. Berger, K.M.; Schneck, P.A. National and transnational security implications of asymmetric access to and use of biological data. Front. Bioeng. Biotechnol. 2019, 7, 1-7. [CrossRef]

89. Wellcome Trust. Sharing Data During Zika and Other Global Health Emergencies. Available online: https:/ / wellcome.ac.uk/news/sharing-data-during-zika-and-other-global-health-emergencies (accessed on 20 October 2018).

90. United Nations. About the Nagoya Protocol. Available online: https://www.cbd.int/abs/about/ (accessed on 14 August 2018).

91. World Health Organization. Pandemic influenza preparedness Framework for sharing of influenza viruses and access to vaccines and other benefits; WHO: Geneva, Switzerland, 2009. Available online: https:/ /www.who. int/influenza/resources/pip_framework/en/ (accessed on 17 March 2019).

92. Ribeiro, C.D.; Koopmans, M.P.; Haringhuizen, G.B. Threats to timely sharing of pathogen sequence data. Science 2018, 362, 404-406. [CrossRef]

93. Christopher, M.M. One health, one literature: Weaving together veterinary and medical research. Sci. Transl. Med. 2015, 7, 303fs36. [CrossRef] 
94. Hitziger, M.; Esposito, R.; Canali, M.; Aragrande, M.; Hasler, B.; Ruegg, S.R. Knowledge integration in one health policy formulation, implementation and evaluation. Bull. World Health Organ. 2018, 96, 211-218. [CrossRef]

95. Wellcome Trust. Sharing Research Findings and Data Relevant to the Ebola Outbreak in the Democratic Republic of Congo. Available online: https:/ / wellcome.ac.uk/what-we-do/our-work/sharing-researchfindings-and-data-relevant-ebola-outbreak-drc (accessed on 2 February 2018). 